\title{
A staggered approach to flash flood forecasting - case study in the Cévennes region
}

\author{
L. Alfieri ${ }^{1}$, P. J. Smith ${ }^{2}$, J. Thielen-del Pozo ${ }^{1}$, and K. J. Beven ${ }^{2}$ \\ ${ }^{1}$ European Commission, Joint Research Centre, Ispra, Italy \\ ${ }^{2}$ Lancaster University, Lancaster, UK
}

Received: 26 July 2010 - Revised: 6 October 2010 - Accepted: 11 October 2010 - Published: 25 February 2011

\begin{abstract}
A staggered approach to flash flood forecasting is developed within the IMPRINTS project (FP7-ENV-20081-226555). Instead of a single solution system, a chain of different models and input data is being proposed that act in sequence and provide decision makers with information of increasing accuracy in localization and magnitude as the events approach. The first system in the chain is developed by adapting methodologies of the European Flood Alert System (EFAS) to forecast flash floods and has the potential to provide early indication for probability of flash floods at the European scale. The last system in the chain is an adaptation of the data based mechanistic model (DBM) to probabilistic numerical weather predictions (NWP) and observed rainfall, with the capability to forecast river levels up to $12 \mathrm{~h}$ ahead. The potential of both systems to provide complementary information is illustrated for a flash flood event occurred on 2 November 2008 in the Cévennes region in France. Results show that the uncertainty in meteorological forecasts largely affects the outcomes. However, at an early stage, uncertain results are still valuable to decision makers, as they raise preparedness towards prompt actions to be taken.
\end{abstract}

\section{Introduction}

The recent flash floods and debris flows that took place on 15 June 2010 in the Var department in France cost 25 lives and caused severe damage (http://www.imprints-fp7.eu). They were caused by unexpected intense and exceptional rainfalls mostly affecting the south-eastern part of France. Some gauging stations recorded more than $300 \mathrm{~mm}$ within $12 \mathrm{~h}$.

This devastating event highlighted once again the need for efficient and reliable early warning systems for flash floods and debris flows. IMPRINTS research project aims at improving preparedness for flash floods and debris flows by staggering hazard and risk identification levels to produce increasingly accurate information as the events draw nearer. This forecasting chain is aimed at leaving end-users with more time for preparatory actions. This is particularly important for sudden and severe flash floods which can be accompanied by devastating landslides, mud flows, damage to infrastructure and heavy death tolls (Collier, 2007). Negative effects of stress on decision-making under time pressure in the operational flood centres can be important (Paton and Flin, 1999) and earlier warnings help in reducing the level of stress and lead to better decisions (Kowalski-Trakofler et al., 2003).

In order to increase warning time beyond a few hours, Numerical Weather Predictions (NWP) need to be employed. However, the longer the lead times, the less precise the output, in particular for severe events. Therefore, meteorologists have designed so called Ensemble Prediction Systems (EPS) (Buizza et al., 2005). The advantage of using ensembles in flood forecasting has been demonstrated for riverine floods (Bartholmes and Todini, 2005; Pappenberger et al., 2005, 2008; Roulin, 2007; Kalas et al., 2008; Thielen et al., 2009) and limited-area EPS (LEPS), specifically designed for capturing small scale, convective and severe events, have been already applied successfully for flash floods (Zappa et al., 2010).

In this paper we illustrate two stages of a four level chain for early flash flood warning for the Gardon d'Anduze; a small, flash flood prone catchment in the Southern France. In Sect. 2 we describe the catchment and the input data, in Sect. 3 the IMPRINTS early warning chain, the models and methodologies. Section 4 illustrates the results for an event on 2 November 2008. Conclusions are drawn in Sect. 5. 


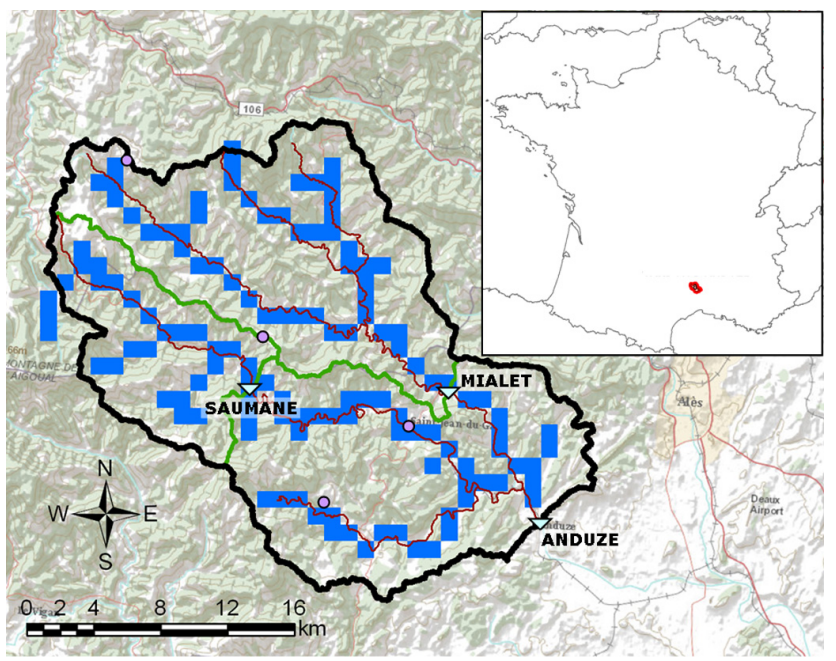

Fig. 1. Map of the Gardon d'Anduze and 1-km river network for the simulated model (in blue). Rain gauges (circles and triangles) and stream gauges (triangles) are also indicated.

\section{Description of catchment and input data}

The Gardon d'Anduze is a small catchment with an area of $544 \mathrm{~km}^{2}$ at the outlet of Anduze. It is located in the Cévennes Mountains of Southern France, a region with mountain peaks up to $1500 \mathrm{~m}$, steep hill slopes and narrow valleys, and it is known for devastating flash floods (Anquetin et al., 2005). The hydrological regime of the Cévennes -Vivarais region is typically low water levels in summer and heavy precipitations causing flash floods mainly in autumn (Chapon, 2006). A schematic view of the catchment is shown in Fig. 1. Rainfall observations within the catchment are available at seven sites with a 5-min resolution from January 2003 to December 2008. Three of the locations (Saumane, Mialet and Anduze) are also stream gauges where water levels are recorded at the same temporal resolution.

NWP are provided by the Consortium for Small-scale Modelling $\left(\mathrm{COSMO}^{1}\right)$. COSMO-LEPS consists of 16 ensemble members, has a spatial resolution of about $7 \mathrm{~km}$ ( $\sim 10 \mathrm{~km}$ before December 2009$)$ and temporal resolution of $3 \mathrm{~h}$ (Marsigli et al., 2005). COSMO-LEPS are calculated daily at 12:00 UTC with a lead time of $132 \mathrm{~h}$. In addition, a meteorological climatology was created (Fundel et al., 2010) from a set of deterministic COSMO hindcasts with $10 \mathrm{~km}$ spatial resolution, 3 hourly, covering the period 1971-2000. These were initialized every 3 days by using ERA 40 reanalysis dataset as initial and boundary conditions. A continuous climatology is obtained by attaching together the data of each subsequent forecast, to produce a seamless meteorological dataset that is coherent with operational COSMO-LEPS forecasts.

\footnotetext{
${ }^{1}$ http://www.cosmo-model.org
}

\section{Description of the hydrometeorological forecasting chain}

In this work, we propose an improved early warning system for flash floods consisting of a chain of methods producing increasingly accurate information. The chain starts with qualitative alert information at the regional level with lead time up to 5 days and follows with local systems producing quantitative information at gauging stations with lead time of few hours. Within the chain, different hydrological models are used providing complementary information, e.g. forecasts of threshold exceedances, discharge and water levels. The idea is that information from top to bottom level improves at the cost of decreasing lead times. The overlap of temporal and spatial range among different models improves the analysis of predictive uncertainty, through increased sample size. Likewise, it makes the forecasting chain more reliable, as it provides backup information in case one of the systems should fail.

Table 1 illustrates the different models used in IMPRINTS. EFAS-FF (see Sect. 3.1) produces the first step in identifying the probability for flash floods to take place. It is designed to provide alerts 1-5 days in advance at the European scale, although within the project is set-up for six testbeds only. EFAS-FF can be applied to both gauged and ungauged catchments. Where a catchment is equipped with automatic gauging stations, then local models (PREVAH, DichiTop, DBM) can be calibrated to assimilate rainfall forecasts and predict discharge or water level at specific outlets. Further, for warning lead time of the order of the catchment lag time, the DBM methodology is used to include previous water stages and get accurate adaptive forecasts at gauged sites.

This paper focuses on the two models that bracket the chain, EFAS-FF and DBM. It illustrates how these models produce sequential and complementary information, upon which the decision support system is based.

\subsection{EFAS-FF, an early indication for flash floods at the european scale}

The concepts for EFAS-FF are derived from the European Flood Alert System (EFAS) described in detail in Thielen et al. (2009) and Bartholmes et al. (2009). EFAS alert rules are based on discharge threshold exceedances where the thresholds have been derived from long-term model simulations and thus represent a model consistent framework. This approach has already been tested successfully for flash floods (Younis et al., 2008; Reed et al., 2007) in a deterministic framework and is here being explored in a probabilistic framework.

The hydrological model of EFAS-FF is LISFLOOD (van der Knijff et al., 2010). For this study LISFLOOD is set up and run on $1 \mathrm{~km}$ horizontal grid and 3-h time step for six testbeds through Europe. For the Gardon d'Anduze, the model parameters are calibrated by using four months of 
Table 1. Hydrological models applied in the IMPRINTS project as well as their spatial and temporal target areas, inputs and outputs within the project.

\begin{tabular}{|c|c|c|c|c|c|c|}
\hline Level & Model & Lead time & $\begin{array}{l}\text { Spatial cover- } \\
\text { age }\end{array}$ & Type & Input data & Output \\
\hline 1 & EFAS-FF & 1-5 days & $\begin{array}{l}\text { Europe, } \\
\text { regional }\end{array}$ & $\begin{array}{l}\text { LISFLOOD, } \\
\text { distributed } \\
\text { hydrological } \\
\text { model }^{\text {a }}\end{array}$ & COSMO-LEPS & $\begin{array}{l}\text { Probability of exceed- } \\
\text { ing critical thresholds } \\
\text { derived from clima- } \\
\text { tology, maps and time } \\
\text { series }\end{array}$ \\
\hline 4 & $\mathrm{DBM}^{\mathrm{d}}$ & $0-12 \mathrm{~h}$ & Catchment & $\begin{array}{l}\text { Data-based mecha- } \\
\text { nistic model }\end{array}$ & $\begin{array}{l}\text { COSMO-LEPS, } \\
\text { nowcasting }{ }^{\mathrm{e}} \text {, radar, } \\
\text { water level } \\
\text { measurements }\end{array}$ & $\begin{array}{l}\text { Water level forecasts } \\
\text { at gauging site }\end{array}$ \\
\hline
\end{tabular}

${ }^{a}$ van der Knijff et al. (2010); ${ }^{b}$ Viviroli et al. (2009); ${ }^{\mathrm{c}}$ Corral et al. (2009); ${ }^{\mathrm{d}}$ Young (2006), ${ }^{\mathrm{e}}$ e.g. Germann et al. (2009) and Atencia et al. (2010)

observed hourly precipitation and discharge measurements collected in 2002, which include data for a major flood event occurred in September. In the others, standard parameters are applied. Critical thresholds are derived from a continuous discharge simulation calculated with the 30-year COSMOLEPS climatology as input to LISFLOOD at the $1 \mathrm{~km}$ resolution. For this, annual maxima are extracted from the discharge climatology. The mean of the annual maxima is used as medium alert threshold, which corresponds to a return period of about 2 years. For higher thresholds, a Gumbel distribution is hypothesized as statistical distribution of the annual maxima of discharge, and an analytical curve is fitted to the set of data previously extracted by applying the method of moments. Values corresponding to return periods of 5 and 20 years are calculated and referred to as high and severe alert threshold. EFAS-FF simulated discharges with COSMO-LEPS as input data are compared against the reference thresholds. Following a set of rules that take into account minimum catchment size, persistence of forecasts and minimum probability of threshold exceedance, a flash flood warning is produced. Threshold values for these rules are being explored through long-term simulations and sensitivity analysis on different case studies.
The hydrological model simulations are activated when one of two indices detect a signal of upcoming flash floods. The first one is based on pre-operational EFAS hydrological simulations ( $5 \mathrm{~km}$ resolution), while the second is the European Precipitation Index based on Climatology (EPIC) (see Alfieri et al., 2010), which gives a measure of forecasted accumulated rainfall at the catchment scale. Model output is flash flood threshold exceedance maps and time series of normalised discharges at pre-selected reporting stations.

\subsection{DBM - data based mechanistic flash flood forecasting model}

Data-based Mechanistic (DBM) modelling is a methodological approach to identifying and estimating parsimonious representations of time-series data (Smith et al., 2009; Ratto et al., 2007; Young, 2006). DBM models are defined inductively. Data are analysed to produce a model that captures their relationships and can be interpreted in a reasonable and physically meaningful manner. Details of the work presented in this section can be found in Smith and Beven (2010).

For compatibility with COSMO-LEPS meteorological forecasts used in this study, the DBM model is here evaluated 
on a $3 \mathrm{~h}$ time step. This is approximately the natural time delay of the system and represents a significant simplification of the catchment response. The model is formulated to predict the maximum water level observed at Anduze within each three hour time step.

The DBM model was identified and estimated (see Young, 2006 for details) from two years (2003-2004) of historical observed rainfall and water level data. The resulting model represents the response of the water level to an effective rainfall as a linear transfer function. In this case the linear transfer function could be interpreted as two parallel paths of rainfall response (i.e. two parallel tanks with different time constants) along with an additional term representing an unfiltered response to the rainfall falling within the same time step. The effective rainfall was computed by multiplying the observed rainfall by $a_{t}^{0.69}$ where $a_{t}$ is the antecedent precipitation at time $t$ computed using exponentially decaying weights.

The Kalman filter is utilised for data assimilation and probabilistic prediction by converting the linear transfer function to a state-space form. Each of the response paths and the direct term is represented by elements of the state vector $\boldsymbol{x}$. Using $y_{t}$ to represent the observed output at time $t$ and $v_{t}$ the effective input, the state-space model can be expressed as

$$
\boldsymbol{x}_{t+1}=\mathbf{F} \boldsymbol{x}_{t}+\boldsymbol{g} v_{t}+\boldsymbol{s}_{t}
$$$$
y_{t+1}=\boldsymbol{h} \boldsymbol{x}_{t+1}+\zeta_{t}
$$

where the matrices $\mathbf{F}$ and $\boldsymbol{g}$ are defined from the parameters of the linear transfer function with $\boldsymbol{h}$ being a suitably sized row vector of ones. The system ( $\varsigma$ ) and observation $(\zeta)$ noise terms were then estimated from unimodal, symmetric and unbounded distributions with zero mean and variances $\mathbf{W} \sigma_{n}^{2}$ and $\sigma_{n}^{2}$, respectively. The subscript indicates that this parameter is dependant upon the forecast horizon of $n$ time steps. The diagonal matrix $\mathbf{W}$ is optimised to minimise the sum of squared errors of the expected values of the predictions pooled over $n=1,2,3,4$. The corresponding values of $\sigma_{n}^{2}$ were then estimated from the standardised residuals to the usual way (Schweppe, 1965).

In the calibrated DBM model for the Gardon catchment there is no time delay so, to generate the forecasts used in calibration of the Kalman filter hyper parameters, it is presumed that the future observations of precipitation are predicted perfectly. Table 2 summarises the calibration results and those for a further year of validation (2005). Note that under the error assumptions above, the expected value of the prediction \pm 3 standard deviations should bracket at least 95 percent of the observations (Pukelsheim, 1994), which is the case.

Using forecast precipitation, rather than the observed precipitation used in the calibration, the prediction of water level requires a number of adaptations to the DBM model forecasting framework. The first adaptation is to calibrate the COSMO-LEPS ensemble members to the rainfall derived
Table 2. Summary of the results of the DBM forecasts (generated using observed rather than forecast precipitation) for multiple lead times.

\begin{tabular}{lrr}
\hline $\begin{array}{l}\text { Forecast horizon } \\
\text { (hours) }\end{array}$ & \multicolumn{2}{c}{$\begin{array}{c}\text { Percentage of points within } \pm 3 \text { standard } \\
\text { deviation of the expected value } \\
\text { Calibration }\end{array}$} \\
\hline 3 & 97 & Validation \\
\hline 6 & 96 & 98 \\
9 & 96 & 98 \\
12 & 96 & 97 \\
\hline
\end{tabular}

from the historical observations. This is achieved by using real time assimilation to provide a magnitude correction (Lees et al., 1994) to the COSMO-LEPS ensemble members. The second is to recognise that the use of the forecast precipitation increases the forecast uncertainty. This is recognised through the application of a variance inflation factor (unique for each forecast horizon) which scales the prediction variances given by forecasting using a member of the corrected COSMO-LEPS ensemble. For a given forecast horizon the variance inflation factor was considered constant in time as well as across ensembles and their members. It can then be estimated as the mean squared error of the appropriately pooled standardised prediction errors. The additional hyperparameters associated with these adaptations were estimated using forecasts based on ten months of COSMO-LEPS ensembles ending in October 2008.

\section{Results}

EFAS-FF and DBM have been set-up and calibrated for the Gardon d'Anduze based on historic data and applied to a flash flood event that took place on the 2 November 2008. $425 \mathrm{~mm}$ of rainfall were accumulated in $48 \mathrm{~h}$ at Croix-deBerthel, about $30 \mathrm{~km}$ north-west of Anduze and $5 \mathrm{~km}$ from the catchment divide, leaving the Gardon d'Anduze only at the fringe of the most affected area. In Anduze, water level rose about $5 \mathrm{~m}$ within one day, producing a peak discharge which corresponds to a 2 year return period.

The European Precipitation Index based on COSMOLEPS Climatology (EPIC, see Alfieri et al., 2010) based on COSMO-LEPS forecast of 30 October 2008 12:00 UTC, indicated a $19 \%$ probability of severe rainfalls in the river basin. This would have activated the $1 \mathrm{~km}$ hydrological simulations for the Gardon d'Anduze. Figure 2 shows a sequence of EFAS-FF results from 30 October 2008 to the 1 November 2008, three to one day before the event. The spatial overview of probabilities of exceeding the medium alert level (MAL, colour coded yellow, top panel) and the high alert level (HAL, colour coded red, bottom panel) are shown. The 
COSMO-LEPS 30/10/2008 12 UTC
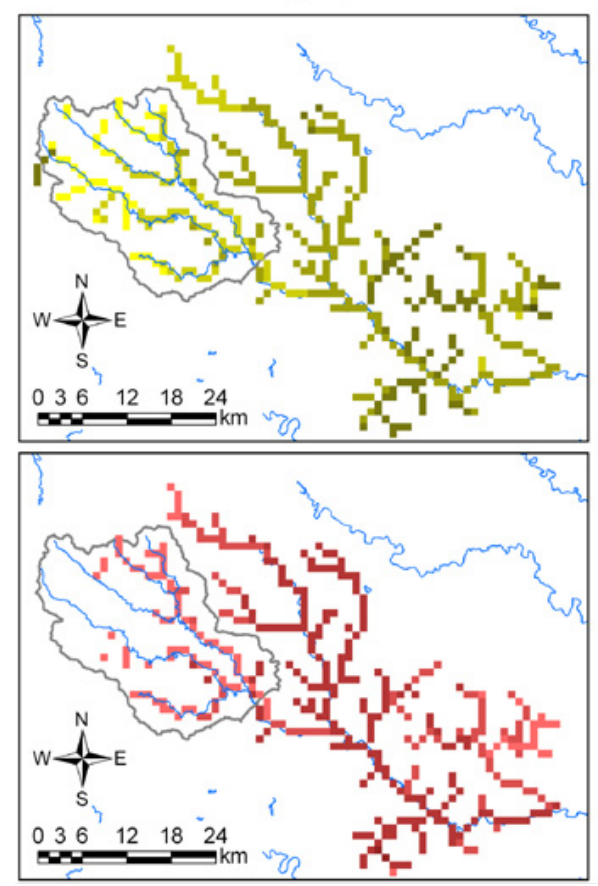

COSMO-LEPS 31/10/2008 12 UTC
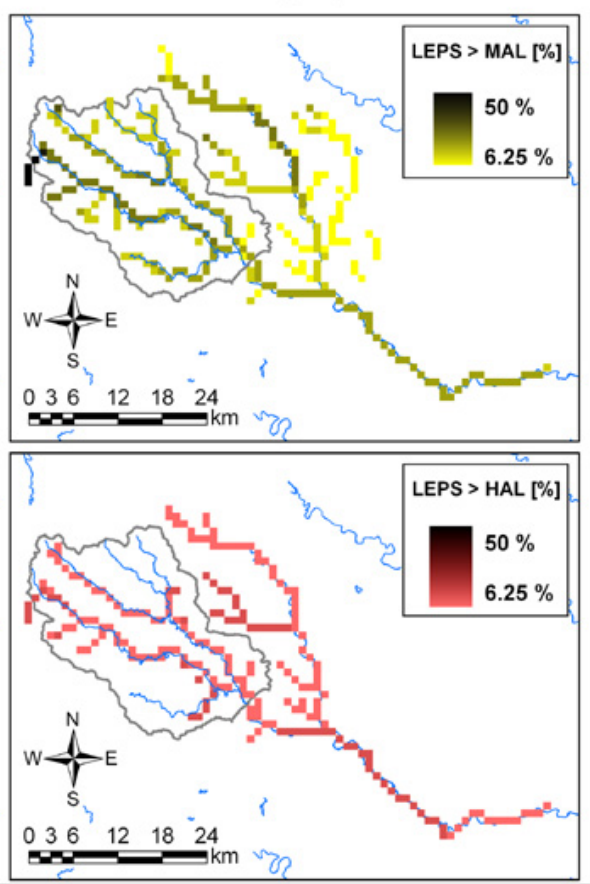

COSMO-LEPS 1/11/2008 12 UTC

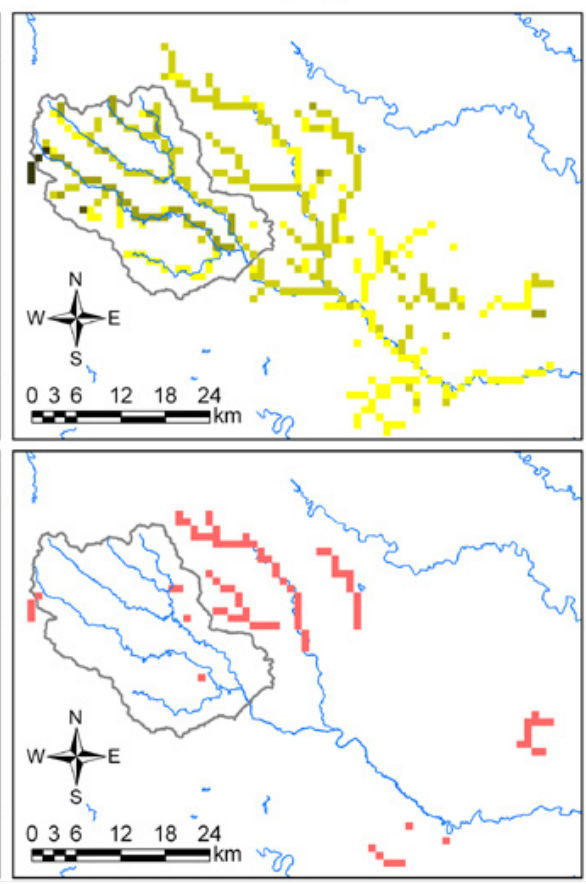

Fig. 2. Probability maps of maximum discharge threshold exceedances for medium (top row) and high (bottom row) alert level in each full forecasting range. Daily COSMO-LEPS forecast at 12:00 UTC are shown from 30 October 2008 (left column) to 1 November 2008 (right column).

maps show the highest probability forecast during the entire forecasting period.

On 30 October there was a $10-40 \%$ probability for the entire region that the high threshold (5 year return period) was exceeded. On the 31 October, the forecasts became spatially more focused in the Gardon d'Anduze and the northeastern neighbouring catchment. However, while there is a probability of almost $50 \%$ that the medium threshold was exceeded, the probability of exceeding the high threshold is comparatively low. Finally, on 1 November the predictions show that the region mostly to be affected remains the northern part, but the forecast intensity decreases further. Exceedance of the high threshold level is predicted only outside the Gardon d'Anduze to the Northwest.

The maps in Fig. 2 show the highest threshold exceedance during the entire forecasting period and do not discriminate for time evolution. This information is provided in Fig. 3 which illustrates time series of EFAS-FF forecast in Anduze. Simulated discharges at every pixel are normalised by the corresponding mean of the annual maxima $\left(\overline{Q_{\mathrm{MAX}}}\right)$ derived from the simulated climatology. The normalisation is useful to remove some sources of bias, due to the quantitative precipitation forecast (QPF), to the hydrological modelling, to the differences in the temporal and spatial resolution of observed and simulated data, and in turn to get comparable warning thresholds. For comparison, the corresponding observed normalised discharge is also shown. Probabilities are colour coded according to percentiles around the median. Figure 3 shows a probability of $12.5 \%$ of exceeding the medium threshold, with the highest prediction forecasting a high alert with discharges of 1.8 times the mean annual discharge (return period $5<T<20$ years). Although only 2 EPS members out of $16(12.5 \%)$ actually exceeded the critical threshold, 2 more members approached the critical threshold. The peak discharge is forecasted $6 \mathrm{~h}$ after the observed one, though this was corrected with the subsequent forecast (not shown). With a warning lead time of $40 \mathrm{~h}$, a shift of $\pm 3 \div 6 \mathrm{~h}$ is well tolerated, and falls within the uncertainty range of this product.

EFAS-FF aims at putting authorities on standby and to activate systems such as DBM, capable of predicting water levels instead of discharges and thus of providing more valuable quantitative information for decision makers. Figure 4 illustrates results of DBM forecasts with lead times of $12 \mathrm{~h}$ for two inputs: the first one (a) is presuming the observed precipitation input was available - in this context a reference prediction and the second (b) is driven with the first $12 \mathrm{~h}$ of COSMO-LEPS predictions.

Driving DBM with reference rainfalls (Fig. 4a) leaves an uncertainty in water level predictions of $\pm 0.25 \mathrm{~m}$ and about $3 \mathrm{~h}$ on the peak timing. The DBM model does not reproduce the falling limb of the event hydrograph correctly. The 
response to a secondary rainfall event is overestimated. This may be due to errors in the observations, particularly the spatial extrapolation of the gauged rainfall to a catchment average; the simplification introduced in the representation of the hydrological system due to the large time step of the model, or the fact that this particular dynamic response of the system was not observed during the calibration. The results indicate that despite the promising calibration and validation results the uncertainty associated with the predictions given by the hydrological model of previous unobserved combinations of catchment input may be underestimated. In contrast, Fig. $4 \mathrm{~b}$ shows considerable uncertainty in water level and timing, highlighting that the COSMO-LEPS precipitation forecasts are a significant source of uncertainty in the forecasting chain, as already found by Jaun and Ahrens (2009). We can conclude that, in order to use probabilistic NWP such as COSMO-LEPS for short-term forecasting up to $12 \mathrm{~h}$ ahead in time, (i) a more complex on-line rainfall calibration methodology than the simple magnitude correction is required; (ii) the uncertainty bounds on the hydrological predictions should reflect when a hydrological event is being poorly forecast due to deficiencies in the hydrological model or precipitation predictions. Options being explored include complementing the magnitude correction on each ensemble member with: (1) a temporal correction to the ensemble member; (2) a weighting scheme which favours those ensemble members with better recent predictive capabilities. In addition to these developments, formulations for state dependant or time varying versions of variance inflation factor outlined in Sect. 3.2 can be proposed. These are analogous to those used for the state-space model variance terms in past DBM applications (Lees et al., 1994; Romanowicz et al., 2008).

Further, a staggering of different rainfall inputs for Probabilistic Flash flood Guidance systems is being explored (see Alfieri et al., 2010) where observations, radar, blending techniques and COSMO-LEPS are combined to increase the forecasting lead time though keeping the uncertainty low for shorter lead time. Such input can also be used in DBM to reduce the forecast uncertainty as the event approaches.

\section{Discussion and conclusion}

Two levels of a staggered flash flood forecasting chain, have been applied to a flash flood case study in the Gardon d'Anduze: EFAS-FF and DBM. Results illustrate how regional systems such as EFAS-FF allow issuing early flood alerts based on the exceedance of critical thresholds. These are derived from long-term simulations with the same hydrological model used for the forecasts and thus are available for every river pixel. The system can be applied also without specific calibration of the hydrological model with observations and has therefore interesting implications for ungauged basins. In contrast, DBM can only be run in river basins

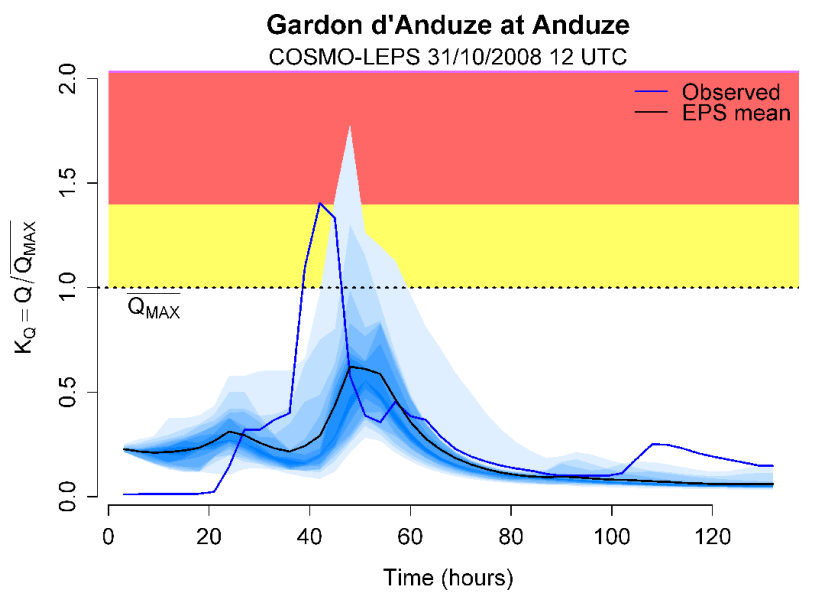

Fig. 3. Ensemble discharge forecast for the Gardon d'Anduze at Anduze (blue shadings around the median) and observations (blue line) for the 31 October 2008 forecast. Rescaled values are plotted for coherent comparison. Medium and high warning ranges are shown in yellow and red, respectively.
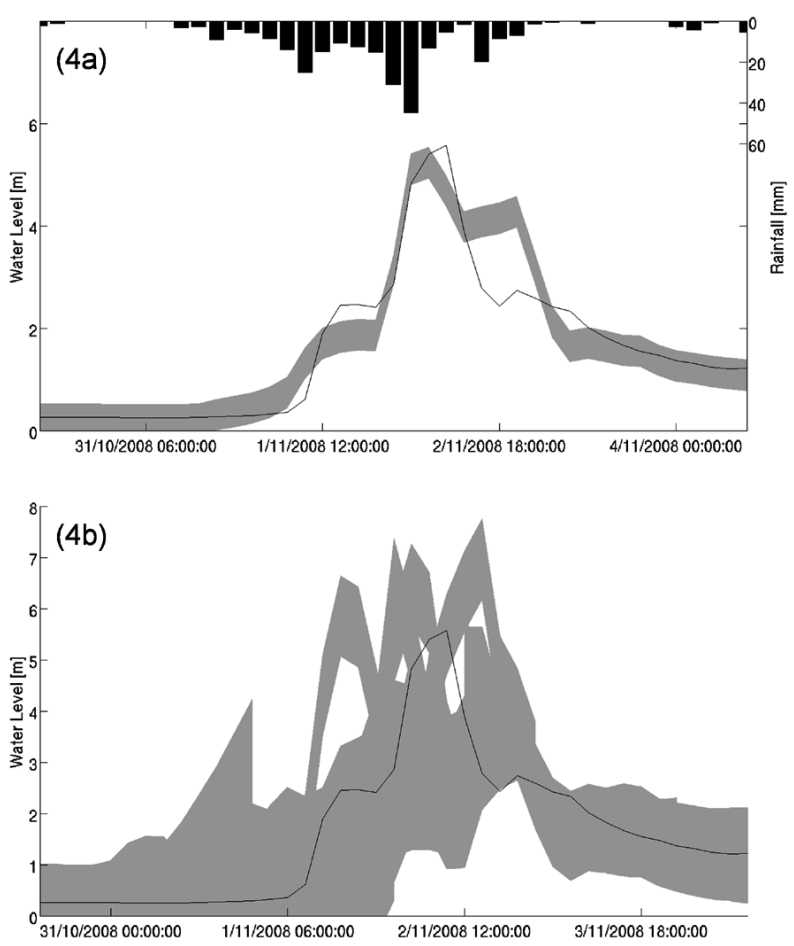

Fig. 4. Twelve hour ahead predictions of water level at Anduze during a flood event in November 2008. The black line shows the observed water levels. On the top panel (a) the forecasts are driven with observed precipitation as input (shown on top). The shaded area represents the expected value of the prediction \pm 3 standard deviations. The bottom panel (b) shows the corresponding predictions when the DBM model is driven by the corrected COSMOLEPS rainfall forecasts. The shaded area represents the prediction intervals (as for (a)) for each of the ensemble members. 
where observations are available and where the model can be calibrated based on prior events. Having these data available, DBM provides forecasts of river level or discharge (Young, 2006), which are valuable for decision makers in the context of flood warning. Working with river levels, rather than discharges, has the advantage that the additional uncertainties introduced by a (possibly non-stationary) rating curve at the site of interest are avoided. The nonlinearity that is included in calibrating the DBM model makes such an approach feasible. This does not impose a mass balance constraint, but can be an advantage if there are consistent errors in either the estimation of catchment rainfalls or in the discharge rating curve extrapolated beyond the range of direct observations.

In both systems the largest proportion of uncertainty is introduced by Numerical Weather Predictions, resulting in large ranges of discharges and water levels. However, even with reference rainfall forecasts, uncertainty remains due to the model parameterisation and formulation of the processes. Overall, using COSMO-LEPS as input yielded in low probabilities of exceeding critical thresholds with both systems. This can be explained by the comparatively coarse spatial resolution of the NPW products. However, cost-benefit analyses show that for rare and severe events, actions may be cost-effective even at low probabilities (Buizza, 2008). This is even more important when human lives are at stake and therefore needs to be accounted for by the decision makers.

This study shows that uncertainties in a flash flood warning and forecasting system should not be ignored. The information coming from different sources and systems can be usefully merged and used in way that appropriate actions can be taken at different times and at different levels of the decision chain until the start of the event. Extensive testing and validation of the proposed system on different case studies is envisaged for the near future, in order to evaluate its sensitivity and optimize the outcomes.

Acknowledgements. The authors acknowledge IMPRINTS financial funding (FP7-ENV-2008-1-226555) and the support of project partners contributing to this work. Particular thanks are given to M. Kalas, M. del Medico and D. Muraro for support in setting up EFAS-FF. Furthermore we acknowledge A. Montani and F. Pappenberger for their support with COSMO-LEPS data, as well as SCHAPI and OHM-CV for providing data for the Gardon catchment.

Edited by: M.-H. Ramos

Reviewed by: M. Zappa and another anonymous referee

\section{References}

Alfieri, L., Velasco, D., Thielen, J.: Flash flood detection through a multi-stage probabilistic warning system for heavy precipitation events, Adv. Geosci., in review, 2011.

Anquetin, S., Yates, E., Ducrocq, V., Samouillan, S., Chancibault, K., Davolio, S., Accadia, C., Casaioli, M., Mariani, S., Ficca, G., Gozzini, B., Pasi, F., Pasqui, M., Garcia, A., Martorell, M.,
Romero, R., and Chessa, P.: The 8 and 9 September 2002 flash flood event in France: a model intercomparison, Nat. Hazards Earth Syst. Sci., 5, 741-754, doi:10.5194/nhess-5-741-2005, 2005.

Atencia, A., Rigo, T., Sairouni, A., Moré, J., Bech, J., Vilaclara, E., Cunillera, J., Llasat, M. C., and Garrote, L.: Improving QPF by blending techniques at the Meteorological Service of Catalonia, Nat. Hazards Earth Syst. Sci., 10, 1443-1455, doi:10.5194/nhess-10-1443-2010, 2010.

Bartholmes and Todini: Coupling meteorological and hydrological models for flood forecasting, Hydrol. Earth Syst. Sci., 9, 333 346, doi:10.5194/hess-9-333-2005, 2005.

Bartholmes, J. C., Thielen, J., Ramos, M. H., and Gentilini, S.: The European flood alert system EFAS - Part 2: Statistical skill assessment of probabilistic and deterministic operational forecasts, Hydrol. Earth Syst. Sc., 13, 141-153, 2009.

Buizza R.: The value of probabilistic prediction, Atmos. Sci. Let., 9, 36-42, 2008.

Buizza, R., Houtekamer, P. L., Toth, Z., Pellerin, G., Wei, M. Z., and Zhu, Y. J.: A comparison of the ECMWF, MSC, and NCEP global ensemble prediction systems, Mon. Weather Rev., 133, 1076-1097, 2005.

Chapon, B.: Etude des pluies intenses dans la région CévennesVivarais à l'aide du radar météorologique. Régionalisation des traitements radar et analyse granulométrique des pluies au sol, $\mathrm{PhD}$ Thesis (in French) University Joseph Fourier, Grenoble, 197 pp., 2006.

Corral, C., Velasco, D., Forcadell, D., Sempere-Torres, D., Velasco, E.: Advances in radar-based flood warning systems. The EHIMI system and the experience in the Besos flash-flood pilot basin. Flood Risk Management: Research and Practice, edited by: Allsop W., Samuels P., Harrop J., and Huntington S., Taylor \& Francis Group, London, ISBN 978-0-415-48507-4, 2009.

Collier, C. G.: Flash flood forecasting: What are the limits of predictability?, Q. J. Roy. Meteor. Soc., 133, 3-23, 2007.

Fundel, F., Walser, A., Liniger, M. A., and Appenzeller, C.: Calibrated precipitation forecasts for a limited-area ensemble forecast system using reforecasts, Mon. Weather Rev., 138, 176-189, 2010.

Germann, U., Berenguer, M., Sempere-Torres, D., and Zappa, M.: REAL - Ensemble radar precipitation estimation for hydrology in a mountainous region Q. J. Roy. Meteor. Soc., 135, 445-456, 2009.

Jaun, S. and Ahrens, B.: Evaluation of a probabilistic hydrometeorological forecast system, Hydrol. Earth Syst. Sci., 13, 10311043, doi:10.5194/hess-13-1031-2009, 2009.

Kalas, M., Ramos, M.-H., Thielen, J., and Babiakova, G.: Evaluation of the medium-range European flood forecasts for the March-April 2006 flood in the Morava River, J. Hydrol. Hydromech., 56, 116-132, 2008.

Kowalski-Trakofler, K. M., Vaught, C., and Scharf, T.: Judgement and decision making under stress: an overview for emergency managers, Int. J. Emerg. Manag., 1, 278-289, 2003.

Lees, M. J., Young, P. C., Ferguson, S., Beven, K. J., and Burns, J.: An adaptive flood warning scheme for the River Nith at Dumfries, in: River Flood Hydraulics, edited by: White, W. R. and Watts, J., John Wiley, Hoboken, 65-77, 1994.

Marsigli, C., Boccanera, F., Montani, A., and Paccagnella, T.: The COSMO-LEPS mesoscale ensemble system: validation of the 
methodology and verification, Nonlin. Processes Geophys., 12, 527-536, doi:10.5194/npg-12-527-2005, 2005.

Pappenberger, F., Beven, K. J., Hunter, N. M., Bates, P. D., Gouweleeuw, B. T., Thielen, J., and de Roo, A. P. J.: Cascading model uncertainty from medium range weather forecasts (10 days) through a rainfall-runoff model to flood inundation predictions within the European Flood Forecasting System (EFFS), Hydrol. Earth Syst. Sci., 9, 381-393, doi:10.5194/hess-9-381-2005, 2005.

Pappenberger, F., Bartholmes, J., Thielen, J., Cloke, H.L., Buizza, R., de Roo, A.: New dimensions in early flood warning across the globe using grand-ensemble weather predictions, Geophys. Res. Lett., 35, L10404, doi:10.1029/2008GL033837, 2008.

Paton, D. and Flin, R.: Disaster Stress: an emergency management perspective, Disast. Prev. Manag., 8, 261-267, 1999.

Pukelsheim, F.: The three sigma rule, Am. Stat., 48, 88-91, 1994.

Ratto, M., Young, P. C., Romanowicz, R., Pappenberger, F., Saltelli, A., and Pagano, A.: Uncertainty, sensitivity analysis and the role of data based mechanistic modeling in hydrology, Hydrol. Earth Syst. Sci., 11, 1249-1266, doi:10.5194/hess-11-12492007, 2007.

Reed, S., Schaake, S., and Zhang, Z.: A distributed hydrologic model and threshold frequency-based method for flash flood forecasting at ungauged locations, J. Hydrol., 337, 402-420, 2007.

Romanowicz, R. J., Young, P. C., Beven, K. J., and Pappenberger, F.: A Data Based Mechanistic Approach to Nonlinear Flood Routing and Adaptive Flood Level Forecasting, Adv. Water Resour., 31, 1048-1056, 2008.

Roulin, E.: Skill and relative economic value of medium-range hydrological ensemble predictions, Hydrol. Earth Syst. Sci., 11, 725-737, doi:10.5194/hess-11-725-2007, 2007.

Schweppe, F. C.: Evaluation of likelihood functions for Gaussian signals, IEEE T. Inform. Theory, 11, 61-70, 1965.
Smith, P. J., Hughes, D., Beven, K. J., Cross, P., Tych, W., Coulson, G., and Blair, G.: Towards the provision of site specific flood warnings using wireless sensor networks, Meteorol. App., 16, 57-64, 2009.

Smith, P. J. and Beven, K. J.: Forecasting river levels during flash floods using Data Based Mechanistic models, online data assimilation and meteorological forecasts, Proceedings of the British Hydrological Society International Symposium, Newcastle, 2010.

Thielen, J., Bartholmes, J., Ramos, M.-H., and de Roo, A.: The European Flood Alert System Part 1: Concept and development, Hydrol. Earth Syst. Sci., 13, 125-140, doi:10.5194/hess-13-1252009, 2009.

van der Knijff, J. M., Younis, J., and de Roo, A. P. J.: LISFLOOD: A GIS-based distributed model for river basin scale water balance and flood simulation, Int. J. Geogr. Inf. Sci., 24, 189-212, 2010.

Viviroli, D., Zappa, M., Gurtz, J., and Weingartner, R.: An introduction to the hydrological modelling system PREVAH and its preand post-processing-tools, Environ. Modell. Softw., 24, 12091222, 2009.

Young, P. C.: The data-based mechanistic approach to the modelling, forecasting and control of environmental systems, Annu. Rev. Control, 30, 169-182, 2006.

Younis, J., Anquetin, S., and Thielen, J.: The benefit of highresolution operational weather forecasts for flash flood warning, Hydrol. Earth Syst. Sci., 12, 1039-1051, doi:10.5194/hess-121039-2008, 2008.

Zappa, M., Beven, K. J., Bruen, M., Cofiño, A. S., Kok, K., Martin, E., Nurmi, P., Orfila, B., Roulin, E., Schröter, K., Seed, A. Szturc, J., Vehviläinen, B., Germann, U., and Rossa, A.: Propagation of uncertainty from observing systems and NWP into hydrological models: COST-731 Working Group 2, Atm. Sci. Let., 11, 83-91, 2010. 